dent speaking "moschetto" (a faulty version of standard Italian) and propositioning her. The originator of this mischief is Ruzzante's compare Menato, who is plotting on his own to sleep with Ruzzante's wife. When the plot misfires, a Bergamask soldier named Tonin wins a sexual encounter with the outraged wife, while the play's ending hints that Menato will also sleep with Ruzzante's wife. The translators explicate the action blow by blow in their Introduction, interpreting motives, clarifying the action, and commenting on the language of the original text.

The translation is faithful to the play's two dialects (Pavano and Bergamask) as well as to a natural-sounding English idiom. In English, Ruzzante's language renews its blunt strength, letting the author's rough-and-tumble obscenities sound as commonplace as the orignal words and expressions did to sixteenth-century listeners. A reader of this translation might be misled, however, by the assertion that Ruzzante's obscenities are rendered "with equivalent English words": "Asshole!" does not translate "Pota" (I.vi) literally, although I believe the translators decided wisely in favor of a stock English expletive, reserving their translation of "pota" ("cunt") for other situations. Sensibly, they have not tried to construct a dialect version of English, or to render Tonin's Bergamask in an idiom different from the Pavano spoken by Ruzzante.

Since the play's central ploy is Ruzzante's attempt to speak falsely in lingua moschetta, more might be said about language, whether the play's use of two dialects or the playwright's approach to the questione della lingua. Two Appendices give alternate versions of a prologue written by Beolco for different performances of the play, and both stress the playwright's attachment to his character's native tongue as natural and thus preferable to another way of speaking: "I see now that when someone wants to say something, right away he changes his own manner of speech and picks up the Florentine or the moschetto, and he says that it wouldn't sound right in his own language" (Appendix I, 115). To be sure, both the term "moschetto" and a comment on Ruzzante's dialects appear in the Notes, but without reference to Beolco's polemic againt a standard literary Italian or to how his use of dialect might influence interpretation of the comedy.

Notes to the Play and to the Appendices and a Selected Bibliography complete a volume that offers English-language readers an accurate, informed, and probably startling first look at a representative work by a playwright recognized as a skillful dramatist and actor not only on stage but in the cultural arena of Renaissance Venice, Ferrara, and Padua.

\title{
NANCY DERSOFI
}

Bryn Mawr College

Juliana Schiesari. The Gendering of Melancholia: Feminism, Psychoanalysis and the Symbolics of Loss in Renaissance Literature. Ithaca: Cornell UP, 1992. Pp. viii, 285.

Juliana Schiesari proposes to describe some of the "symptomatic moments" in the history of melancholy, defined as a particular "discursive practice" of the fifteenth to twentieth centuries. Her intention is to "broach an articulation" of the fields of psychoanalysis and "Renaissance scholarship" and to examine the systemic exclusion of women from "the canon of melancholia." More broadly, she hopes thus to "deconstruct the rules 
of patriarchal supremacy" ( $69 \mathrm{n.28}$ ) and to set in their place a female discourse that will legitimate women's power through a revision of psychoanalysis, not merely "undo the ego" as the "privileged site of consciousness" but also to show that the emotions, "that disparaged realm of supposed femininity," constitute "a positive form of social and psychical reasoning" (266-67). Enlisting a host of writers - Freud, Luce Irigary, Kaja Silverman, Julia Kristeva, Aristotle, Ficino, Hildegard of Bingen, Petrarch, Gaspara Stampa, Isabella di Morra, Tasso, Robert Burton, "Hamlet," Lacan and Walter Benjamin, Schiesari "situates" melancholic texts by male authors in relation to others by women, using a framework of ideas partly developed in her initial discussion of Freud's 1917 essay "Mourning and Melancholia."

There are two traditions about melancholia in the West: the mainstream is the medical, stemming from Hippocrates and Galen; it posits an abnormal and undesirable condition affecting both body and mind. The literary tradition, peculiar to the Renaissance and modern era, proposes that melancholy is not altogether evil, because it confers unusual intellectual and artistic powers. Schiesari notices the existence of the medical theory only to repudiate it. Melancholia, she declares, "is to be understood as a cultural category rather than as a medical one" (234). She seems to mean not that medicine is not a part of culture but that melancholia is not a real "disease"; it is simply a way of talking by men that aims at "derealizing the mother and recuperating the feminine from a male position" (75-76). In the Renaissance a "melancholy male pathos" was constructed which empowered men to produce valued cultural artifacts - poetry, philosophy whereas mourning, women's special mode of expressing their unhappiness, was devalued as a space for self-representation and self-display.

Freud stands at the confluence of the two traditions. He thought melancholia an illness, but one that conferred greater sensitivity, and especially a keener moral conscience. Hamlet was his perfect exemplar. He defined Hamlet's disease as an imaginary sense of lack of something unknown, which operates like an "open wound," draining cathectic energies. The ego identifies itself narcissistically with the lost object, which it incorporates within itself. Schiesari comments: "The melancholic's narcissistic relation to lack (the "open wound") seems to qualify the condition as a male strategy to assuage the fact of castration, that is, to deny the fear of sexual difference" (57). According to Schiesari, the ego's sense of poverty is just a "pretext" through which it can represent itself as suffering. The lost object is idealized: in the Renaissance, for example, it becomes an idealized past or some form of transcendence.

Schiesari elaborates Freud's theory, that the melancholy ego is split, one-half assuming a critical superiority over the "inferior" half, as follows: "this object, at once vilified, desired and judged by a 'superior, moral' instance, is situated in the same way as woman in classic phallocentrism" (9). That the abject part of the ego is equated with the feminine side of men she considers evidenced by the roles given to Ophelia and Gertrude in Hamlet of "persistent objects of . . . aggressivity and derision" (10).

Rejecting the "phallocratic" aspects of Freud's theory, and modifying it by Lacan's, Schiesari reads backward in history, psychoanalyzing Ficino, Tasso and Hamlet, and arguing that in every case melancholy is an occasion for narcissistic self-display and repression of the feminine. Ficino victimized himself vis-a-vis God and wished to "castrate" (i.e., discard) his earthly body; thus he expressed a rejection of the feminine, while also necessarily identifying "himself" with "the female victim" (presumably, his own body). Hildegard of Bingen is read as a correction to Ficino, though she wrote three centuries earlier when "noble melancholy" was unheard-of. Schiesari calls her Causae et 
curae a "radical reinterpretation of melancholy as devolutionary regression" (144). It is simply, in all major respects, a product of the mainstream medical tradition. (Schiesari herself notes at the beginning of her discussion of Hildegard that the Abbess's "negative" view of melancholy may not be surprising, given her "entrenchment" in medieval thought; but she then seems to forget this observation.)

She finds that Tasso's poetry everywhere exemplifies his castration fear and need to "recuperate" his eros by victimizing himself and denying the feminine. Gaspara Stampa and Isabella di Morra, on the other hand, laudably "reaffirm mourning as an intersubjective space wherein loss is represented" (166). Their poetic grief over frustrated love and imprisonment is really mourning for "the generalized loss of possibilities women suffer under patriarchal dominance by their lack of an accredited lack" (169). But when Tasso laments his mother's death he is guilty of "appropriating [it] . . . as if it were his own loss and victimization" and finding "satisfaction in his own melancholic voice" (185).

This book succeeds in showing us a new way to approach melancholy - to deconstruct it as a cultural idea or moment. Schiesari here exposes some intellectual strategies of the patriarchy not yet much explored in this field. Along the way she offers many provocative readings and arresting observations, as for example, that a "good" woman is one of whom there is nothing at all to say (109).

I have some doubts, however, about her methods. It may be that reading backward from a twentieth-century perspective poses considerable problems in contextualization. For example, I find her assessment of Hildegard's achievement partially unconvincing. The meaning of Hildegard's work, as revolutionary or not revolutionary, will be perceived for what it is only when one sets it in its historic context. The same criticism can be levied, even more forcefully, upon her treatment of Burton's The Anatomy of Melancholy, which, on the strength of one small passage in a very large book, Schiesari would like to place in the Ficinian tradition of inspiring melancholy, whereas the whole weight of the book rests on the medieval medical tradition. Schiesari's method is the proof-text one: certain passages are abstracted and privileged with some transcendent meaning above the whole work. By this means Schiesari is able to make such dubious claims as that Burton is a blatant misogynist, or that he thinks "reason" is the sovereign cure for melancholy. In fact, Burton's "Love-Melancholy" leads to the conclusion that not women but frustration of desire by over-rigid laws is the cause of erotomania, in men and women. And the Anatomy is a vast testimonial to the inadequacy of reason and "male" authority. In any case, it is very hard to see how Burton's "reason" is unproblematically to be equated with "obsession," "hysteria," and "the witch-burning craze" (246).

The context that is most sorely missing from this book is that of medieval culture. Medieval thought is much more acute and complex than Schiesari seems to think and Burton's book is much more medieval than she imagines. Her allusions to medieval literature look like the gleanings of one who has read it only to search for evidences of misogyny: even courtly-love romances signify mainly that women are the cause of male melancholy. She seizes upon the allegorical personifications of abstractions so common in the Middle Ages. The figure of "Dame Merencolyie" in Alain Chartier's Traite de l'esperance shows that men attribute melancholy to some kind of "feminine onslaught." "Male reason seems to be the cure" (99). But any nodding acquaintance with medieval 
literature will inform us that Reason, too, is usually personified as a female, as are Health, Wisdom, Strength, Force, Patience, and Fortitude.

The application of psychoanalytic theory to works of Renaissance literature remains a doubtful proposition, as this book will illustrate. Schiesari reviews the criticisms that have been levied against it, especially those "infamous" ones of Stephen Greenblatt, who denounced its ahistoricism and its illegitimate imposition of a "universalizing mythology" on all texts and periods. She promises instead to "historicize." Nevertheless, throughout the book she pursues an argument about the "transhistorical oppression of women's losses in Western phallocentrism that exceeds any neo-historicist insistence on the particularity of a single historical moment" (17). Nor is the universalizing mythology absent. The Oedipus complex is everywhere invoked: all motions of the male psyche seem in this book to be mere epiphenomena of that traumatic phase. But we can assign unconscious motives to people long dead only by essentializing shamelessly. Although Schiesari often writes eloquently in defence of difference, there are ways in which her method denies difference.

Nowhere are these difficulties more acutely felt than in the curiously bifurcated discussion of Hamlet in Chapter V. Hamlet is located neither in a play, nor in the consciousness of his creator (Shakespeare is barely mentioned), nor yet exactly in the consciousness of Freud, though that is probably where he should be placed. He is a kind of floating signifier. But since we have no context for his existence, except in a seventeenth-century play, we must look to that for information about what Hamlet says and does, and clues as to what "he" might have intended. When we do that, we shall be dissatisfied with many of Schiesari's statements about him. According to her, he is a hollow, posturing pretender to "sensitivity" and "greatness." The crucial moment in his story is that of his rejection of Ophelia, which creates "a kind of eros predicated on selfproduction through the fetishistic exploitation of . . woman" (260). He has suffered no "real" losses, compared with those of Gertrude and Ophelia (whose tragedy this really is), "only a sense of lack." But his loss is imaginary: it it merely "an impossible union . . . understood as the loss from [sic] heaven" (262). His behaviour to women is savage, but with Claudius he is always "cautious and even gentle," deciding not to kill him in favour of "speaking daggers" to his mother instead (240). These interpretations make nonsense of the play by relying on snippets of text without regard to real, not imaginary, contexts. The rat behind the arras is forgotten. In her long excursus on whether or not four months is a short time to mourn a husband, Schiesari fails to take the obvious step of consulting social histories to find out what was considered decent. She verges on congratulating Gertrude for getting "the work of mourning" done efficiently (241).

Schiesari shows that she can write lucid, witty prose at places in this book, for example, in her narration of Tasso's life. But she usually employs the jargon-written, syntactically tortured style that has become the badge of authority in some theoretical circles, a sort of blessed stigmata. Her tone also tends to annoy: male writers and characters are unfailingly castigated and females are treated with exaggerated respect, offensive to common sense. There are signs that the day is dawning when feminist writers can drop this stance: perhaps we can look forward to a more independently conceived style in the next book of this undoubtedly talented critic.

PATRICIA VICARI

University of Toronto 